\title{
Predictors for Work Participation in Individuals with an Autism Spectrum Disorder: A Systematic Review
}

\author{
Anja Holwerda $\cdot$ Jac J. L. van der Klink • \\ Johan W. Groothoff $\cdot$ Sandra Brouwer
}

Published online: 24 January 2012

(c) The Author(s) 2012. This article is published with open access at Springerlink.com

\begin{abstract}
Introduction Research shows that only about $25 \%$ of people with autism are employed. Method We conducted a systematic review on factors facilitating or hindering work participation of people with autism in longitudinal studies. An extensive search in biomedical and psychological databases yielded 204 articles and 18 satisfied all inclusion criteria. We assessed the methodological quality of included studies using an established criteria list. Results Seventeen factors were identified and categorized as disease-related factors, personal factors or external factors. Limited cognitive ability was the only significant predictor consistently found for work outcome. Functional independence and institutionalization were both reported by one study to be significantly related to work outcome. Inconsistent findings or non significant findings were reported for the other fourteen factors. Conclusion These findings emphasize the need for more high quality cohort studies focussing on work participation as the main outcome among people with Autism.
\end{abstract}

\footnotetext{
A. Holwerda · J. J. L. van der Klink - J. W. Groothoff .

S. Brouwer

Department of Health Sciences, Community and Occupational Medicine, University Medical Centre Groningen, University of Groningen, Building 3217, Room 621, P.O. Box 196, 9700 AD Groningen, The Netherlands
}

\footnotetext{
A. Holwerda $(\bowtie)$

Department of Health Sciences, Community and Occupational Medicine, University Medical Centre Groningen, University of Groningen, Building 3217, Room 621, Antonius Deusinglaan 1, 9713 AV Groningen, The Netherlands

e-mail: a.holwerda@med.umcg.nl
}

Keywords Autism $\cdot$ Work participation $\cdot$ Predictors

\section{Introduction}

Work participation is considered as an increasingly important health outcome [1]. On the individual level it contributes to health and welfare [2]. On the societal level demographic pressure due to ageing and shrinking populations make a broad participation more and more imperative. At the same time participation in work by vulnerable groups is complicated by increasing demands in work. Young disabled people willing to enter the workforce experience barriers in acquiring and retaining work. Despite the relevance and although the impact of autism on social outcomes has been described in quite a few studies in the existing literature [3-7], the body of knowledge regarding factors facilitating or hindering work participation of people with autism is limited.

Autism

Autism, a life-long lasting developmental disability, affects social functioning, behavior, learning and cognition $[8,9]$. According to Kobayashi et al. [3] three in four individuals with autism also have intellectual disabilities. Autism spectrum disorders (ASD) seem to be more prevalent in boys than girls [10].

Autism and Work Participation

Adults with autism have typically not been considered suitable candidates for employment in the work force $[8,11,12]$. Especially the social deficits typical for most 
people with autism hinder their integration in the work force [4, 13]. Research shows that only about $25 \%$ of people with autism are employed. These are mostly the more high-functioning individuals. Unemployment rates for individuals with ASD as well as mental retardation are especially high [14]. They are mostly in sheltered employment, if employed at all [15].

Notwithstanding these limitations, there are several opportunities for work for these young disabled people, like regular work (including supported employment), sheltered employment, daytime activity or voluntary work [8]. People with autism can benefit from employment socially as well as personally [11]. Employment can provide a daytime structure that is helpful for this group as well as social contacts that are otherwise difficult for them to maintain $[8,11,16]$. Having a job also may facilitate their self-confidence, selfworth, independence and autonomy $[11,17]$.

Factors Associated with Autism and Work Participation

The available reviews describing autism and social outcome suggest that the majority of individuals with autism is unable to lead an independent life, including employment [13, 18-20]. Most individuals suffer (severe) persisting impairments in communication and social life limiting their independence and social functioning considerable, especially as demands on social adaptation and functioning increase with age [7, 13, 19]. Howlin [6] suggests that, as far as high functioning individuals are concerned, employment levels may be more dependent on the area individuals live in and the available support services than on any other factors. Also access to supported employment programs for this group may increase chances to find and retain appropriate jobs $[6,21]$. IQ, communicative speech at 5-6 years of age, the level of mental retardation, and other comorbidity are mentioned as important predictors for outcome in individuals with ASD [18-20, 22];. Of those with a comorbid intellectual disability (IQ scores $<50$ ) few are capable of employment. Outcome for individuals with an IQ between 50 and 70 is more variable, but not much better. Outcome for individuals with an IQ of 70 or more seemed to be more promising but also more difficult to predict [6, 18-20, 22]. Besides deficits in cognitive and social functioning, limited independent performance and high dependence on caregiver support are considered important contributors to restricted outcome for individuals with ASD [9, 13].

To our knowledge, the literature on factors associated with work participation in adulthood for people with ASD has not yet been reviewed systematically. In a recent review factors influencing the work participation of young disabled starters entering the labor market were identified [23]. They found that male gender, higher education, high psychosocial level of functioning, low depression and high dispositional optimism were promoting factors in relation to employment. However, in their review no studies on autism were included.

The aim of this review is to systematically investigate the prognostic factors facilitating or hindering work participation of people with ASD.

\section{Methods}

We started conducting a systematic review of the scientific literature on prognostic factors related to work participation of people with ASD. However, we found only one study focussing on factors in relation to work outcome as a primary outcome measure; in most studies work outcome measures were incorporated in an overall social outcome. Therefore, we decided to include also studies looking at overall social outcome, incorporating employment, which provided valuable information about work outcome as well. Studies on overall social outcome including employment, not reporting on work outcome specifically, were not included. The International Classification of Functioning was selected as an underlying framework because it takes the multidimensional nature of work participation into account and provides a broad view on predictors [1].

The first $(\mathrm{AH})$ and second reviewer (SB) discussed search strategy, criteria for selecting studies, quality assessment and data extraction to reach consensus. In case of disagreement the third reviewer $(\mathrm{JvdK})$ made the final decision.

\section{Literature Search}

An extensive search in biomedical and psychological databases was performed (PubMed, PsycINFO, Embase, Cinahl, ERIC, SocINDEX) to find relevant articles, using $\mathrm{MeSH}$ terms, subheadings and free text words. Original studies (in English, Dutch, German and French) were identified that were published till June 2011. Only longitudinal studies were included to be able to distinguish predictors of work outcome. The search strategy consisted of an autism component and a work-related outcome measure.

In Table 1 the search terms are presented.

To select relevant studies for this review, the following eligibility criteria were defined: (1) Studies reported on factors related to work participation or social outcome in people with autism, only if information about work participation or employment status were included; (2) autism had to be diagnosed during childhood by an expert (e.g. following DSM-IV or ICD-10 criteria). The inclusion criteria are: 
Table 1 Search terms

$(*=$ truncated $)$

\begin{tabular}{|c|c|c|}
\hline Terms linked to & $\mathrm{MeSH}$ & Free text words \\
\hline Diagnosis & $\begin{array}{l}\text { Child development disorders, } \\
\text { pervasive * Asperger syndrome } \\
\text { autistic disorder }\end{array}$ & $\begin{array}{l}\text { Autism autistic disorder pervasive } \\
\text { developmental disorder Asperger } \\
\text { syndrome }\end{array}$ \\
\hline Population & & Exclusion: child and not adult \\
\hline $\begin{array}{l}\text { Outcome } \\
\text { measure }\end{array}$ & $\begin{array}{l}\text { Work employment (exploded) rehabilitation, } \\
\text { vocational (exploded) vocational guidance }\end{array}$ & $\begin{array}{l}\text { Career employment/employed/ } \\
\text { employee(s) occupation vocation job }\end{array}$ \\
\hline $\begin{array}{l}\text { Study } \\
\text { design }\end{array}$ & $\begin{array}{l}\text { Cohort studies longitudinal studies } \\
\text { prospective studies follow-up studies }\end{array}$ & $\begin{array}{l}\text { Cohort longitudinal prospective } \\
\text { follow-up prognostic }\end{array}$ \\
\hline
\end{tabular}

- Types of studies: Cohort studies, follow-up studies or longitudinal studies with a minimum follow-up period of 1 year.

- Types of participants: Persons in the age bracket 18-64 years, with disability due to autism spectrum disorder, diagnosed before the age of 18 .

- Types of outcome measures: Dependent variables: participation in work (regular, supported or sheltered) or social outcome with a work identifiable component.

Titles and abstracts were screened independently by two reviewers $(\mathrm{AH}, \mathrm{SB})$. Full papers were retrieved if the abstract provided insufficient data to enable selection. Moreover, other relevant articles were searched on the basis of the name of the first author of included articles and the reference lists. Reviews were excluded, but their reference lists were inspected for additional studies.

\section{Data Extraction}

Using a standardized form, the first reviewer (AH) extracted data on study design, source population, inclusion criteria, numbers of participants, length of follow-up, loss to follow-up, outcome, prognostic factors and statistical analysis. Meta-analysis of the study results was not possible due to the descriptive nature of the included studies, the different outcome measures used and the limited availability of data which could be used for pooling.

Assessment of Methodological Quality of Included Studies

Two reviewers (AH, SB) independently assessed the methodological quality of all included articles in the final selection. The quality assessment of the selected studies was based on an established criteria list for assessing validity of prognostic studies, as recommended by Altman [24] and used in previous reviews [25, 26]. The internal validity was the main aspect judged to inform the reader about the quality of the studies regarding the aim of our review.

The criteria list consists of 16 items, each having yes/no/ don't know answer options. We operationalized the criteria for this review and pilot tested this operationalization on four longitudinal studies excluded for this present review. The final criteria list is presented in Appendix [27].

The quality of all included articles was scored independently by two reviewers (AH, SB). If sufficient information was available, the item was rated one point. When information was not given or the information given was unclear, the item was rated zero point. For the total quality score we added all points for each study (maximum score 16 points).

Studies with a minimum score of 11 points $(\geq 70 \%)$ were arbitrarily considered to be of high quality and those with a score lower then 11 points $(<70 \%)$ of low quality. This cut-off score is in line with a previous review [26]. We calculated initial interobserver agreement on methodological quality using kappa statistics for dichotomous values.

\section{Results}

\section{Selection of Studies}

The initial search yielded 204 articles (search date: June 6th, 2011). After selecting 19 references for full text reading, both reviewers agreed to include 14 articles for the present review. Two articles were excluded because they were intervention studies. Three articles did not report on specific employment outcomes. Searching the reference lists of those included articles, we found and included 3 additional articles. Based on the name of the first author of the 17 included articles, we found 1 other relevant article. Figure 1 shows a flow chart of study selection. In total we included 18 articles for the present review [3-5, 7, 28-41] (Table 2).

\section{Study Characteristics}

The characteristics of each study regarding country, design, measurements, population, numbers enrolled, time to follow-up and loss to follow-up are presented in Table 2 . Time to follow-up varied considerably within as well as 


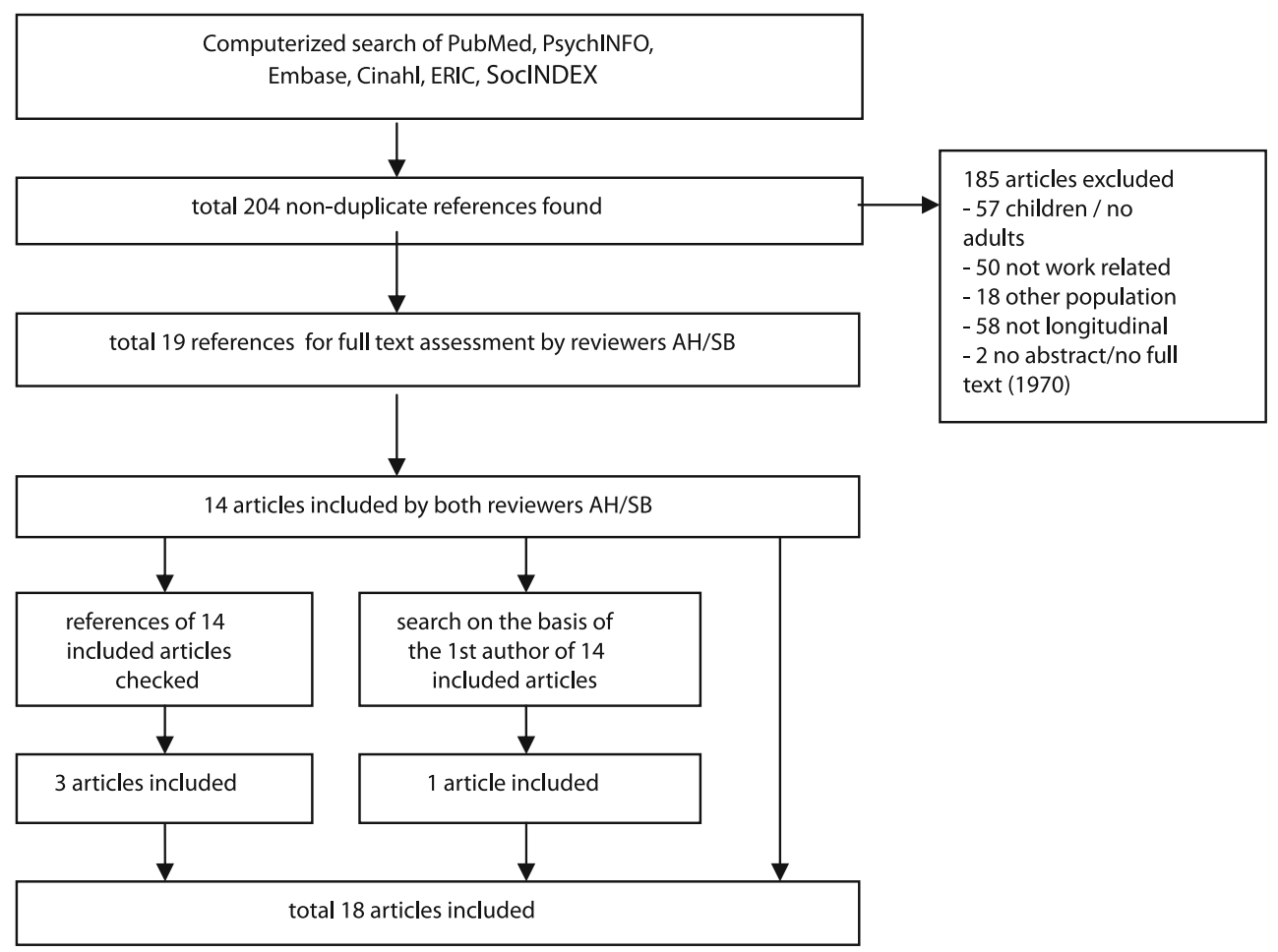

Fig. 1 Flow diagram of study selection

between studies, with the minimal time to follow-up being 3.2 and 35 years at most.

\section{Quality Assessment and Methodological Considerations}

The final overall agreement between the two reviewers on quality score was $\kappa=0.80$, which is considered to be acceptable. Disagreement originated mainly from reading errors and misinterpretation of the criteria list and was readily resolved in a consensus meeting. The methodological quality of all included studies is summarized in Table 3. Four studies were considered of high methodological quality and fourteen of low quality. Statistical pooling of data in a meta-analysis was not possible because of the heterogeneity of study population and quality of the included studies.

\section{Predictors for Work Participation}

Seventeen different prognostic factors were identified. In Table 4 an overview of these factors related to work outcome is presented per included study. Table 5 gives an overview of these factors. The prognostic factors are categorized as disease/disorder related factors, personal factors or external factors based on the ICF-model [42, 43]. The only significant predictor for work outcome, consistently found in fifteen studies, is intelligence. Functional independence and institutionalization were reported in two separate low quality studies to be significantly predicting work outcome. Inconsistent findings were reported for diagnosis, severity of disorder, gender, language abilities, and maladaptive behavior. Non significant findings were reported for comorbidity, social impairments, lack of drive, parental support, family income, mental illness parents, family situation, treatment/ use of medication and schooling.

\section{Disease Related Factors}

\section{Diagnosis}

Six studies found that the more severe the disorder the lower the chance on a good outcome [5, 28, 36, 37, 39, 40]. With regard to work participation, one study reported that individuals who were competitively employed had significantly fewer autism symptoms than those who had a supported job or were participating in adult day activity programs [40].

\section{Comorbidity}

Comorbidity (psychiatric disorder, oppositional personality or epilepsy) was mentioned by five studies as negatively influencing work outcome $[5,30,38-40]$. No evidence was found that use of medication hinders a favorable work outcome [33]. 


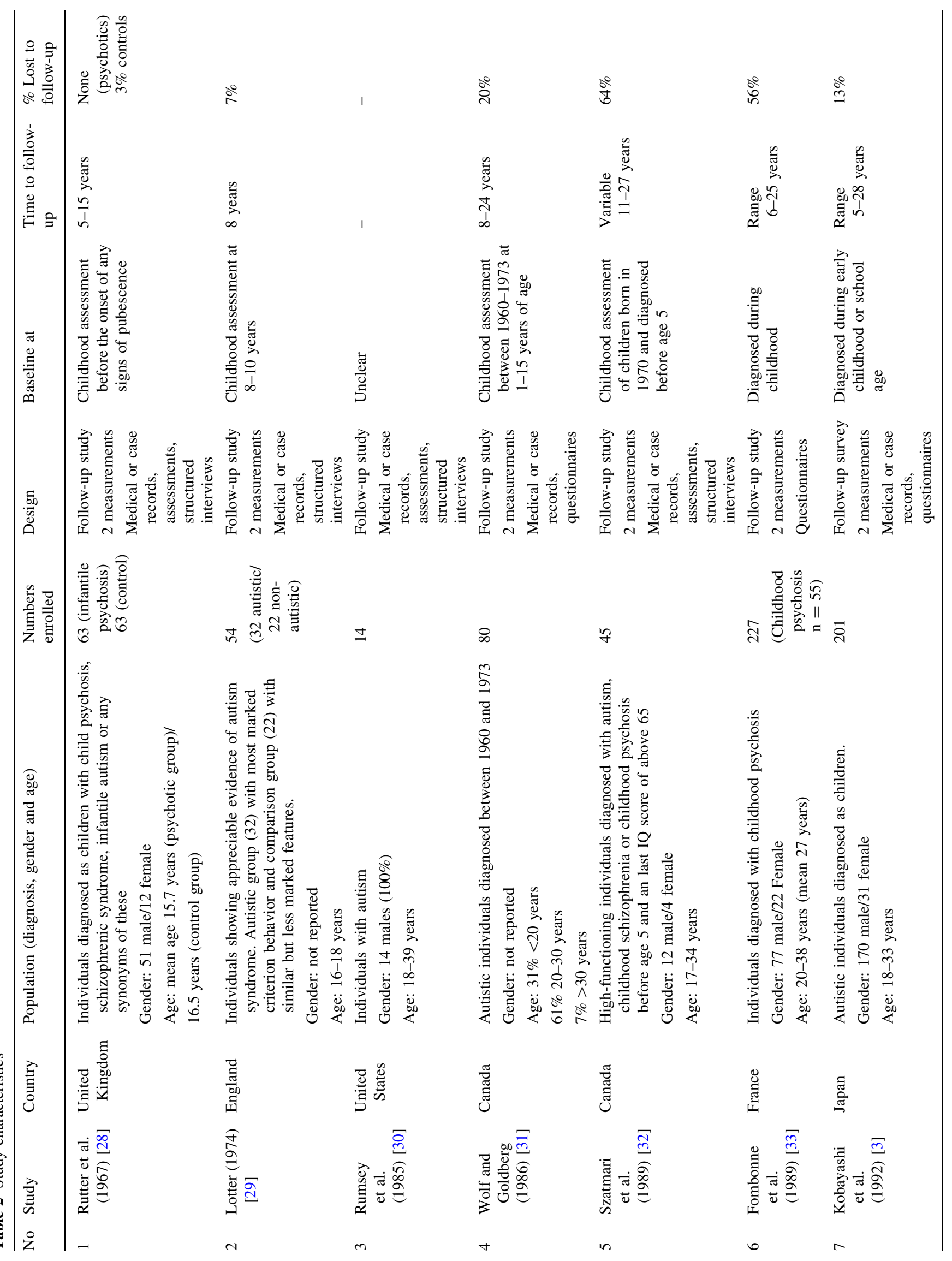




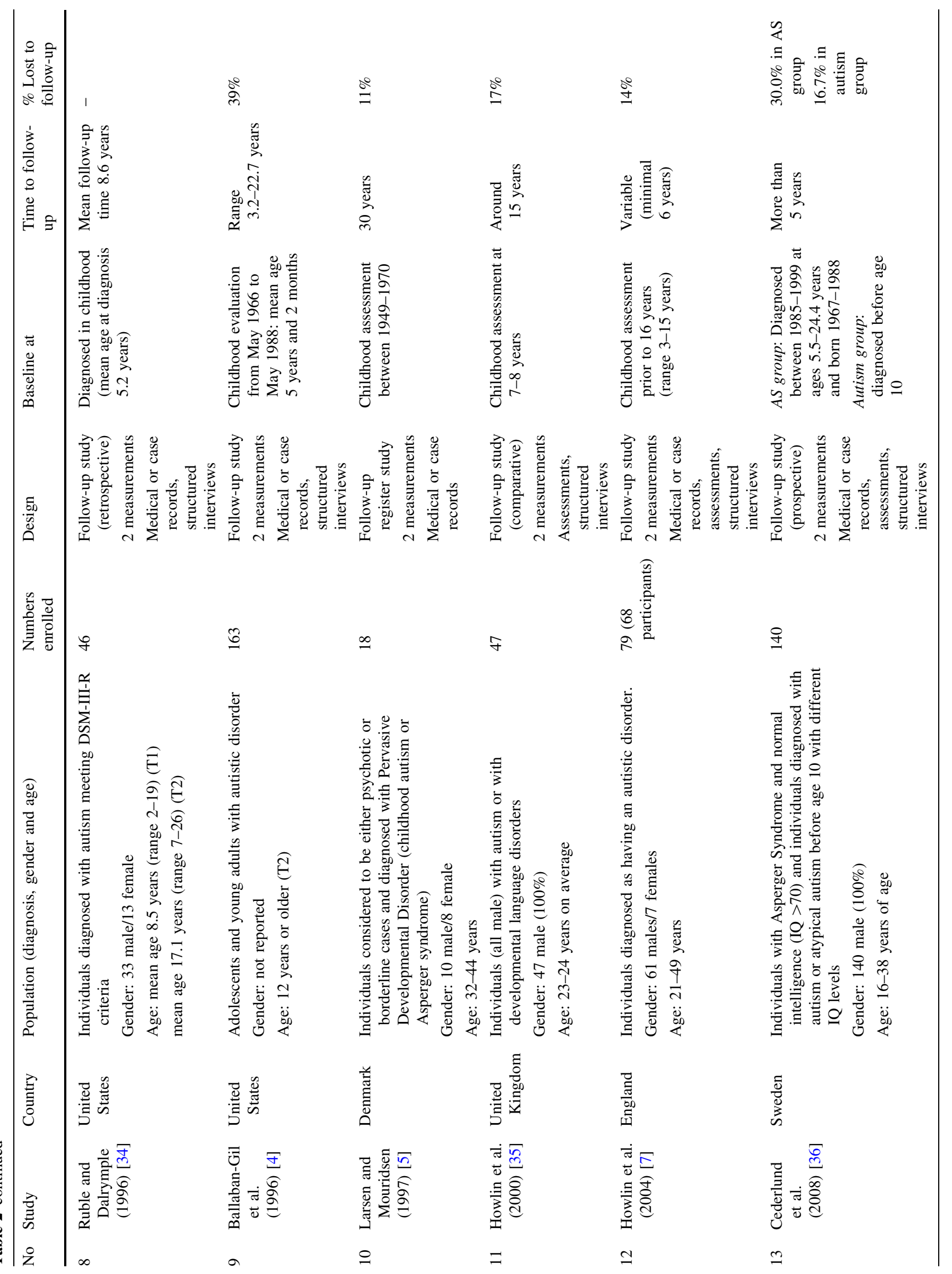




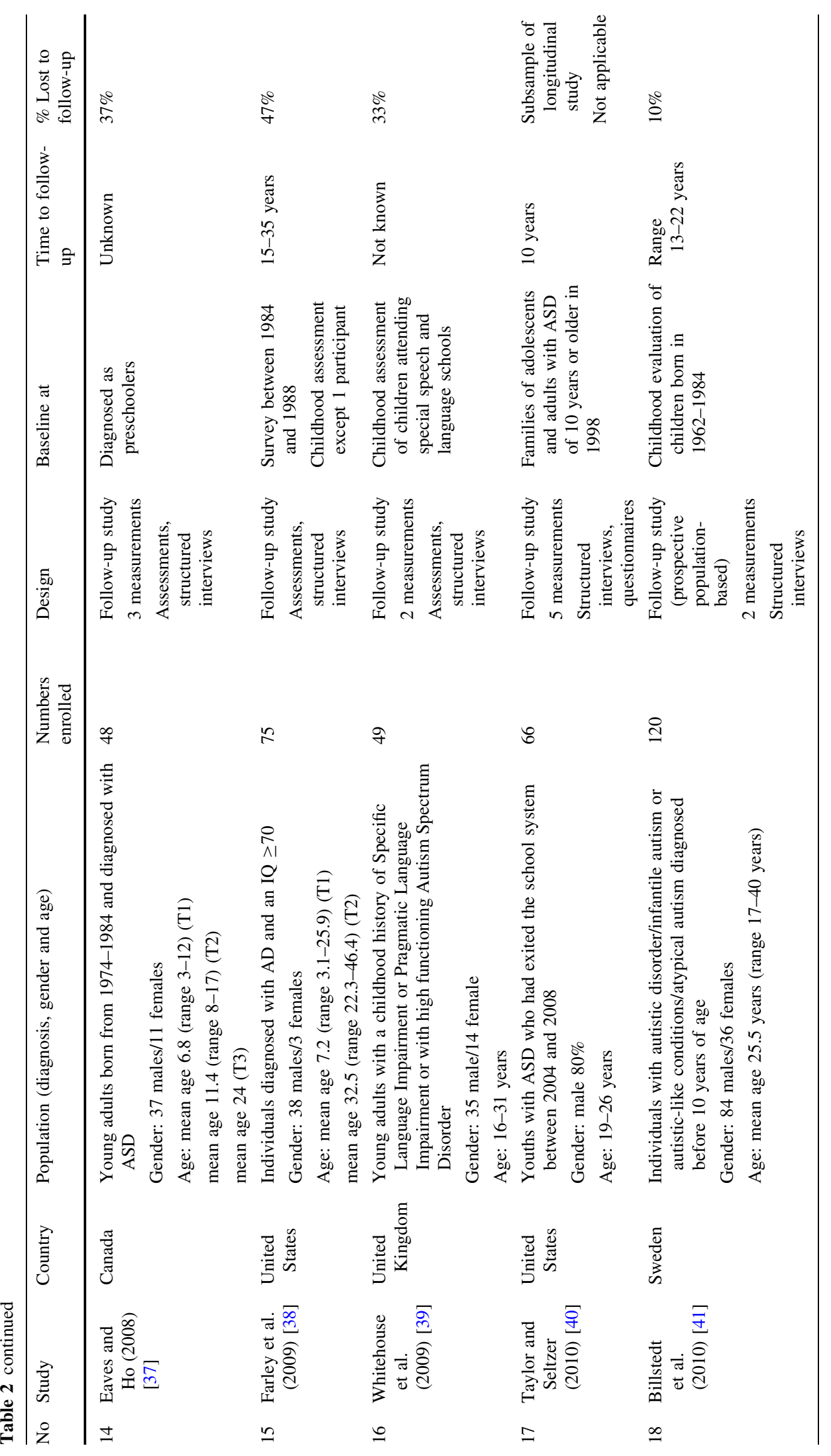


Personal Factors

\section{Gender}

In two studies gender was mentioned as a predictor for outcome, in that females might be more likely to have a poor outcome than males [7, 31]. In a third study [33] female gender was not found to be a hindering factor for positive outcome.

\section{Intelligence}

Higher IQ facilitates a positive work outcome [3-7, 28, 3134, 36-38, 40, 41]; see also [22, 44]. One study reported that all individuals involved in competitive employment had an IQ above 70 [31] and another reported that individuals with a stable IQ above 70 were more often in some form of employment [7]. Individuals without intellectual disability were three times more likely to be competitively employed than individuals with an intellectual disability [40]. Higher IQ was significantly correlated to having a daily occupation [41]. According to Howlin [6, 7] individuals of higher IQ in general had a better outcome and problems were less pervasive (see also [4, 28, 30]). IQ $<50$ is often associated with poor outcome [28]. Fombonne et al. [33] found a significant worse outcome for the group with an IQ of 80 or below. In the study of Larsen and Mouridsen [5] normal intelligence predicted good outcome.

\section{Language/Speech}

Language abilities and level of useful speech may influence outcome in that better linguistic abilities might support better outcome [3, 4, 6, 7, 28, 31, 38, 39]. However, speech may be highly correlated with IQ [7, 32]. Howlin compared an autism group with a developmental receptive language disorder group and found that early language abilities appeared to be closely related to later adult functioning in the autism group [6]. Kobayashi reported that the positive effect of early speech development only occurs in males and not in females [3]; Rutter found that the level of speech at 5 or 6 years of age was closely related to IQ and low IQ contributes significantly to poor outcome [28].

\section{Maladaptive Behavior}

The presence of odd, challenging or ritualistic behavior, including self-injury, aggression and uncooperative behaviors, interferes with daily functioning [3, 4, 6, 7, 28, $30,32,34,38-40]$. Individuals in post-secondary education or competitively employed had significantly lower levels of maladaptive behaviors than individuals receiving day services [40]. Szatmari found a high correlation between adaptive behavior and IQ [32]. According to some authors behavioral difficulties can be a critical limiting factor for functioning successfully in employment [4, 30].

\section{Social Impairments}

The presence of social impairments, the lack of social skills and empathy are associated with poor outcome [4, 7, 29, $30,32,39]$. It is suggested that social impairments are likely to affect the ability of individuals with autism to find and remain in meaningful employment [45].

\section{Education}

The relationship between education and employment for individuals with autism seems to be ambiguous. The majority of people with autism have attended special education services and many left school without any formal qualifications $[6,7,28,30,33,36,37,39]$. However, people with high functioning autism have more often completed post-secondary education than other individuals with ASD [36]. In Lotter's study [29] all individuals with good and fair outcome had had at least 7 years of education. In spite of the educational attainment of high-functioning individuals, few of them were competitively employed and if employed often in routine jobs [29, 30].

\section{Lack of Drive}

Underactivity, lack of drive and lack of initiative often hinder people with ASD to find competitive employment [28]; see also [29, 30]. Lotter [29] mentioned three necessary requirements for being able to participate in regular employment: practical competence (e.g. literacy, practical skills), social competence (being able to relate to people in a meaningful way) and intentional competence (e.g. taking initiative, motivation).

\section{External Factors}

\section{Family}

Parents play a major role in the outcome of their children with ASD. Many individuals with ASD continue to live with their family well into adulthood. According to Wolf and Goldberg [31] 87 percent of the individuals residing at home were involved in schools, workshops or independent work, compared to 46 percent in institutions.

Seven articles mentioned parents searching for job opportunities and finding jobs for their children or providing a job in a family business rather than finding a job through the open job market [3, 6, 7, 28-30, 32]. Howlin et al. [7] commented that for individuals to be able to 
Table 3 Results of methodological assessment ${ }^{\mathrm{a}}$

\begin{tabular}{llrrrrrrrrrrrrrrrrrrrrrrrr}
\hline No & Study & A & B & C & D & E & F & G & H & I & J & K & L & M & N & O & P & Score & Quality \\
\hline 1 & Rutter et al. (1967) [28] & 0 & 1 & 0 & 1 & 1 & 0 & 1 & 0 & 1 & 1 & 1 & 1 & 1 & 1 & 0 & 0 & 10 & Low \\
2 & Lotter (1974) [29] & 1 & 1 & 0 & 1 & 1 & 0 & 1 & 0 & 0 & 0 & 0 & 1 & 1 & 1 & 0 & 0 & 8 & Low \\
3 & Rumsey et al. (1985) [30] & 0 & 0 & 1 & 0 & 0 & 0 & 0 & 0 & 1 & 1 & 1 & 1 & 1 & 1 & 0 & 0 & 7 & Low \\
4 & Wolf and Goldberg (1986) [31] & 0 & 1 & 0 & 1 & 0 & 0 & 1 & 0 & 1 & 1 & 1 & 1 & 1 & 1 & 0 & 0 & 9 & Low \\
5 & Szatmari et al. (1989) [32] & 0 & 1 & 1 & 1 & 0 & 1 & 1 & 0 & 1 & 1 & 1 & 1 & 1 & 1 & 0 & 0 & 11 & High \\
6 & Fombonne et al. (1989) [33] & 0 & 1 & 0 & 1 & 0 & 1 & 1 & 0 & 1 & 1 & 1 & 1 & 1 & 1 & 0 & 0 & 10 & Low \\
7 & Kobayashi et al. (1992) [3] & 0 & 1 & 0 & 1 & 1 & 0 & 1 & 0 & 1 & 1 & 1 & 1 & 1 & 1 & 0 & 0 & 10 & Low \\
8 & Ruble and Dalrymple (1996) [34] & 0 & 0 & 0 & 1 & 0 & 0 & 1 & 0 & 1 & 1 & 1 & 1 & 1 & 1 & 0 & 0 & 8 & Low \\
9 & Ballaban-Gil et al. (1996) [4] & 0 & 0 & 1 & 1 & 0 & 1 & 1 & 0 & 1 & 1 & 1 & 1 & 1 & 1 & 0 & 0 & 10 & Low \\
10 & Larsen and Mouridsen (1997) [5] & 0 & 1 & 0 & 1 & 1 & 1 & 1 & 0 & 1 & 1 & 1 & 1 & 1 & 1 & 0 & 0 & 11 & High \\
11 & Howlin et al. (2000) [35] & 0 & 0 & 1 & 1 & 1 & 0 & 1 & 0 & 1 & 1 & 1 & 1 & 1 & 1 & 0 & 0 & 10 & Low \\
12 & Howlin et al. (2004) [7] & 0 & 0 & 1 & 1 & 1 & 1 & 1 & 0 & 1 & 1 & 1 & 1 & 1 & 1 & 0 & 0 & 11 & High \\
13 & Cederlund et al. (2008) [36] & 0 & 1 & 1 & 1 & 0 & 0 & 1 & 0 & 1 & 1 & 1 & 1 & 1 & 1 & 0 & 0 & 10 & Low \\
14 & Eaves and Ho (2008) [37] & 1 & 1 & 0 & 1 & 0 & 0 & 1 & 0 & 1 & 1 & 1 & 1 & 1 & 1 & 0 & 0 & 10 & Low \\
15 & Farley et al. (2009) [38] & 0 & 1 & 1 & 1 & 0 & 0 & 1 & 0 & 1 & 1 & 1 & 1 & 1 & 1 & 0 & 0 & 10 & Low \\
16 & Whitehouse et al. (2009) [39] & 0 & 0 & 0 & 1 & 0 & 1 & 1 & 0 & 0 & 0 & 0 & 1 & 1 & 1 & 0 & 0 & 6 & Low \\
17 & Taylor and Seltzer (2010) [40] & 0 & 1 & 1 & 1 & 0 & 0 & 1 & 0 & 1 & 1 & 1 & 1 & 1 & 1 & 0 & 0 & 10 & Low \\
18 & Billstedt et al. (2010) [41] & 0 & 1 & 1 & 1 & 1 & 0 & 1 & 0 & 1 & 1 & 1 & 1 & 1 & 1 & 0 & 1 & 12 & High \\
& Total & 2 & 12 & 9 & 17 & 7 & 6 & 17 & 0 & 16 & 16 & 16 & 18 & 18 & 18 & 0 & 1 & & \\
\hline
\end{tabular}

a See Appendix for operationalization of items A-P

function adequately as adults the degree of support offered by families, social services and work environment may be as important as intellectual ability.

\section{Institutionalization}

Institutionalization (i.e. hospitalization) hinders a positive outcome of individuals with ASD. Especially the lower functioning individuals are living in residential care, like special institutions and hospitals where staff can attend to their specific needs. Also quite a few individuals with ASD were part of day time programs in a specialized setting $[5-7,28,30,31,36]$. These settings might not be the stimulating environment people need to be able to grow in their competences and work skills, although this applies to individuals with ASD as well as without $[8,16]$.

\section{Work Outcome}

The selected studies used different, but comparable, outcome measures regarding work participation and overall social outcome (incorporating education/employment, independent living and social relationships). Jobs were generally low level, unskilled and low pay jobs $[4,7,30,37]$. Some individuals, however, managed to find a higher level job. Most individuals received special assistance in finding employment.

Few reasons are given for individuals previously employed but no longer participating in work. Rumsey [30] mentioned one individual was fired because of inappropriate social behavior. Kobayashi [3] mentioned conflicts with fellow employees, financial crisis, motivation, hospitalization and other personal circumstances (death of a parent) as causes for quitting a job. Larsen and Mouridsen [5] mentioned loss of supportive parents, divorce and factories closing down as hindering factors for finding permanent employment.

\section{Conclusion and Discussion}

This study identified seventeen factors related to work outcome of people with ASD. Most of these factors are of importance for all individuals with or without autism. However, it may not be just one single factor, but the combination that leads to limited employment outcomes. Especially in individuals with ASD were a combination of these factors occurs frequently. Some of these factors may be interdependent, making interpretation of the results more complex. For example, some studies found high correlations between IQ and language abilities and IQ and adaptive behaviour in individuals with ASD. The disorder related characteristics (intensity of autistic symptoms, psychiatric comorbidity and epilepsy) and personal characteristics (limited language abilities, behavioral problems, social impairments) typical for ASD are factors which may, separately or combined, hinder individuals with ASD to participate in work in a sustainable way. Rates of 


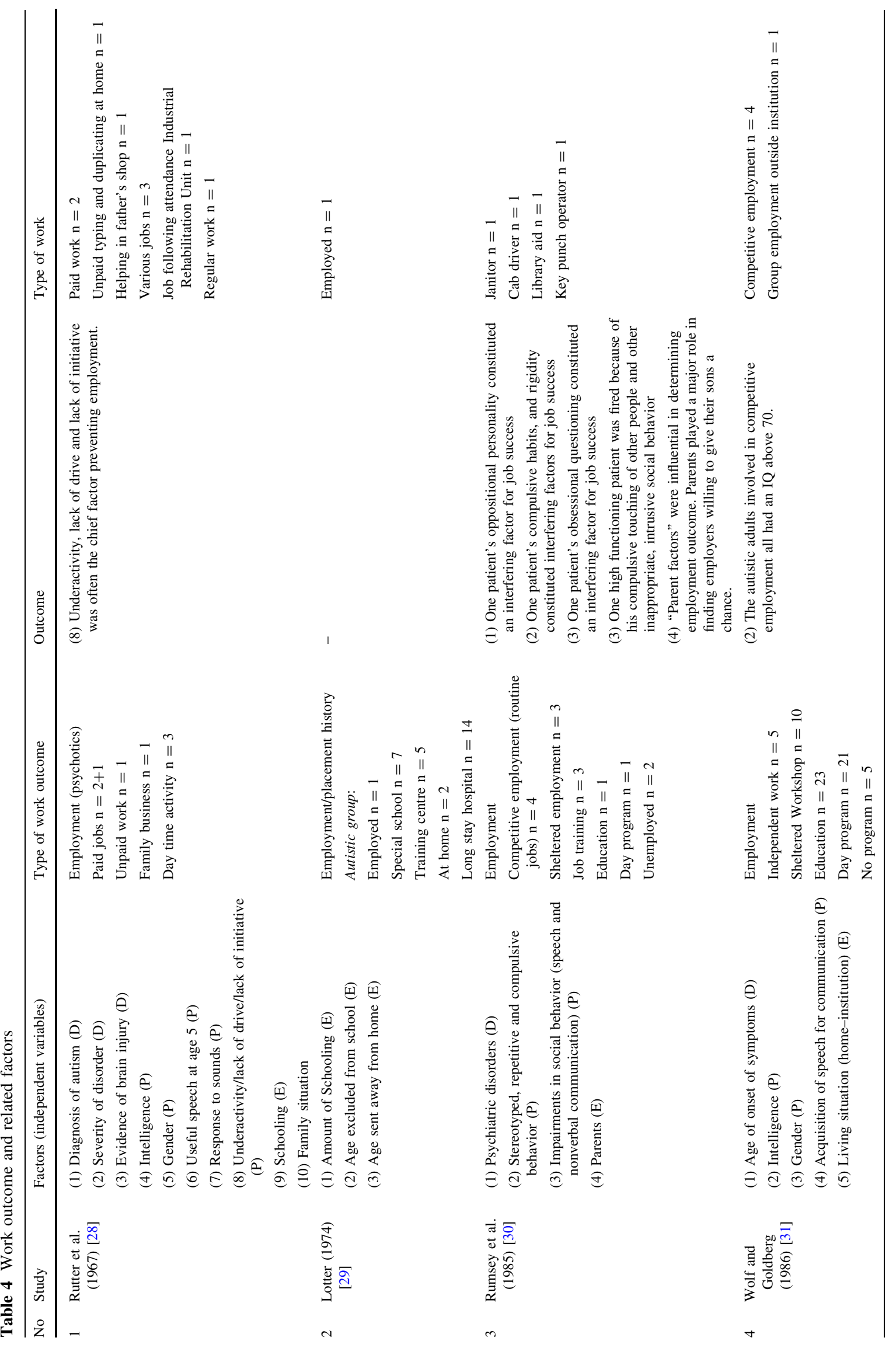




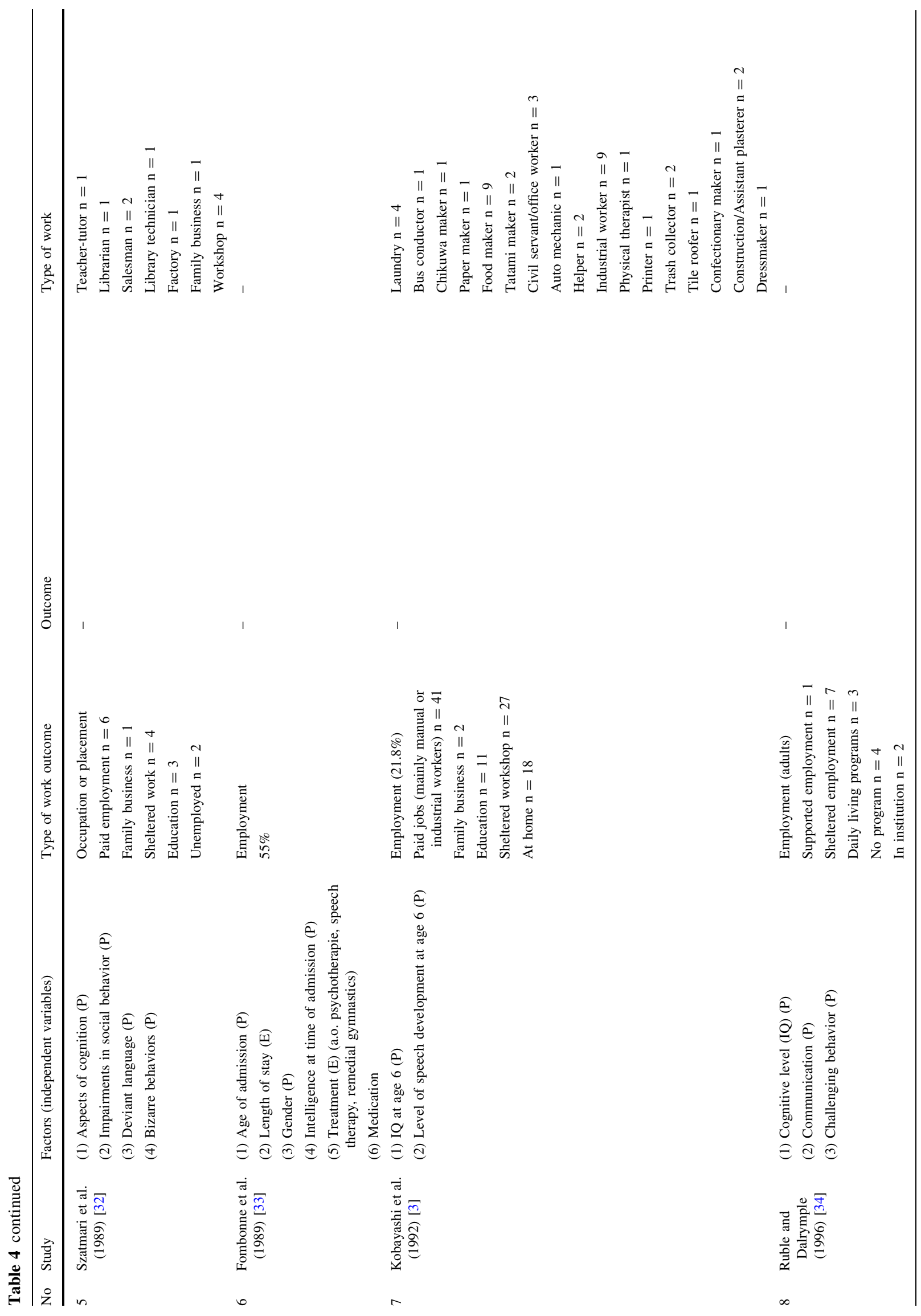




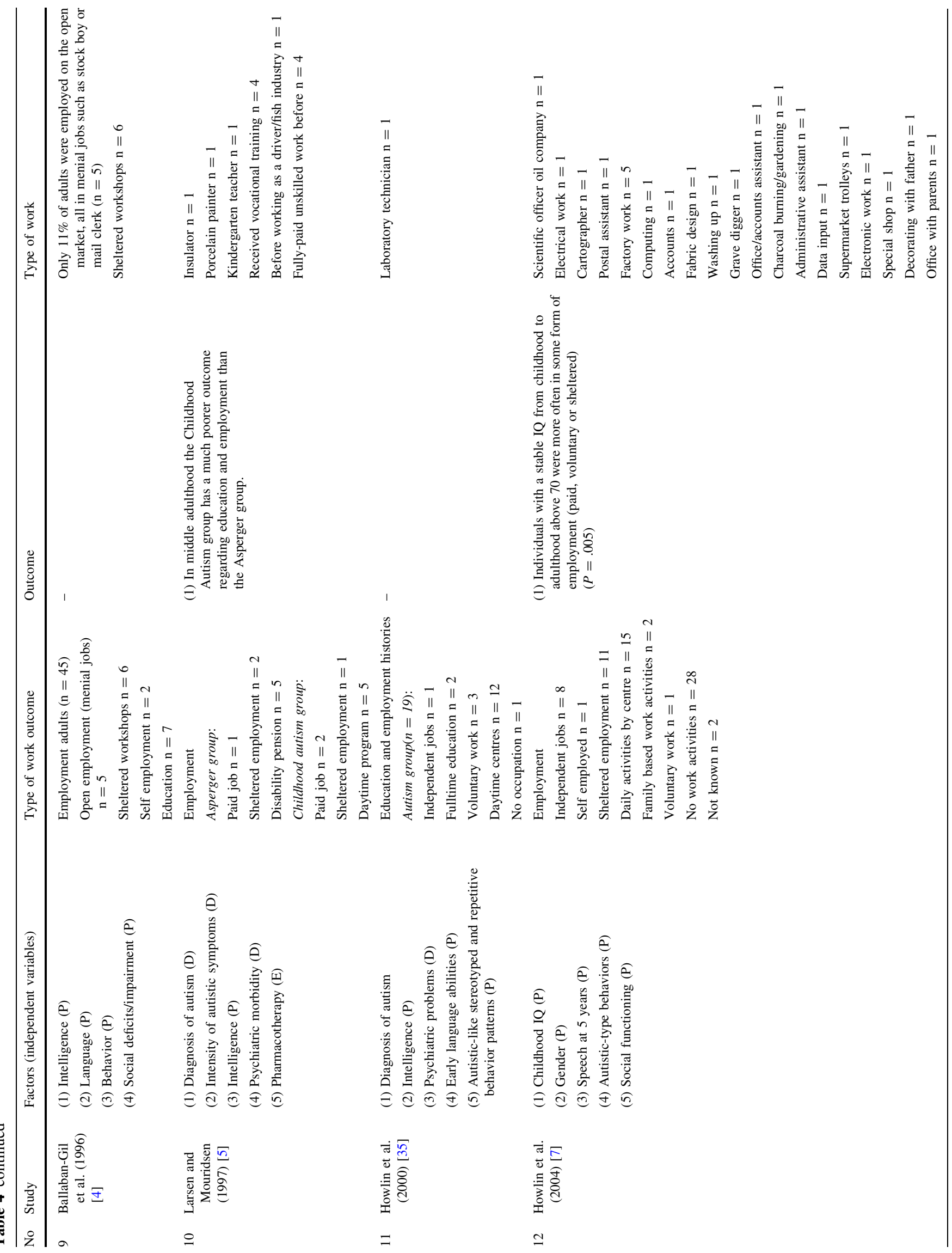




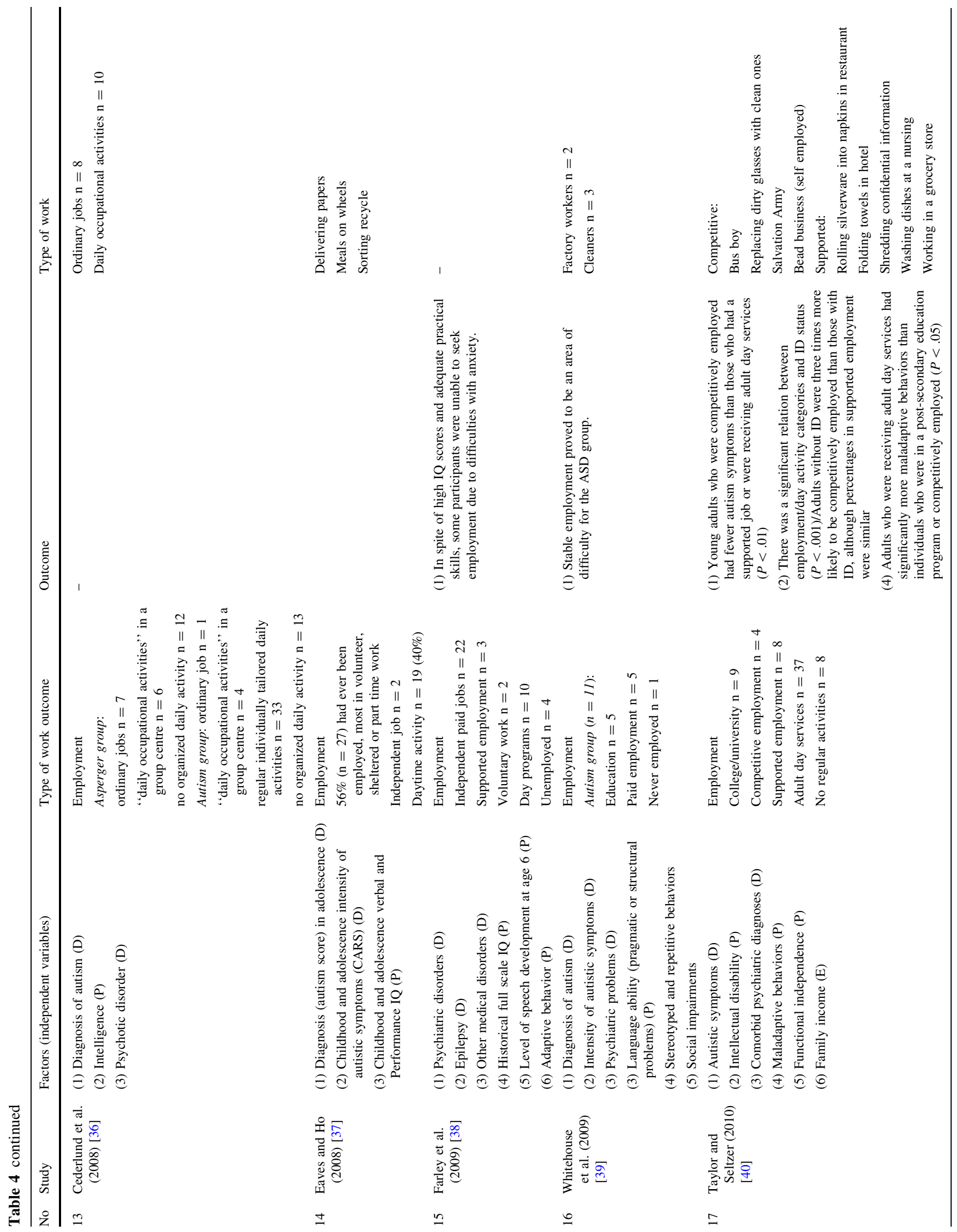


employment among individuals with ASD are generally low. Often the impairments and social deficits of these individuals are emphasized leading to low expectations regarding outcome. However, these individuals may have strengths (e.g. ability to concentrate; strong focus) that can be utilized if the right tasks and settings are provided [22].

In some of the studies Asperger syndrome and Childhood Autism were separately analyzed. There is a continuing discussion whether it is possible and necessary to distinguish between childhood autism and Asperger syndrome [22, 46, 47]. A pronounced autistic disorder often leads to substantial limitations in participation in work; people with Asperger Syndrome often achieved higher education and have more abilities to work compared to childhood autism. However, this advantage in education does not always lead to higher levels of employment in later life [46].

IQ is the only childhood predictor of work outcome for which we found consistent evidence in the literature in that a higher IQ facilitates a positive work outcome. Although an IQ below 50 does almost always lead to a poor outcome [7] and this applies to individuals without ASD as well [48, 49], individuals with an IQ of 70 or higher do not necessarily have a good outcome. Outcome in individuals without intellectual disability is much more variable and less predictable. Therefore, it seems that the clinical value of IQ in predicting individual outcomes is limited.

Although education is often mentioned as an important factor for outcome, job level is rarely consistent with educational background. Also the increase in educational services for children with ASD has not necessarily led to improved outcome when they have grown up [7]. As access to education can be closely associated with the IQ of the individual, this relationship must be regarded with caution [18]. Nevertheless there is some evidence that the amount of schooling received, positively influences social adjustment in later life [18, 49].

Besides disorder-related and personal factors, several external factors are related to work outcome. Considering the low levels of independence of individuals with ASD, the degree of support offered by families, the available support services and the willingness of employers to incorporate this group in their work force may be as decisive for individuals to be able to function adequately in employment as the personal factors mentioned above $[7,50]$. Especially parents play an important role in supporting their children as they continue to live with them well into adulthood, in searching for job opportunities and in being advocates for their child's well-being $[6,7]$.

Competitive paid employment is often regarded as successful participation. Because of increasing demands in work, employers are hesitant to hire individuals with disabilities. If working, many individuals with ASD work in unskilled, routine, industrial jobs with limited decision 
Table 5 Overview of factors associated with outcome

\begin{tabular}{|c|c|c|c|}
\hline Prognostic factors (independent variables) & Study & Significance & Quality of study \\
\hline \multicolumn{4}{|l|}{ Disease/disorder related } \\
\hline \multicolumn{4}{|l|}{ (Autism) diagnosis } \\
\hline \multirow[t]{5}{*}{ (Autism) diagnosis } & Rutter et al. (1967) [28] & n.s. & Low \\
\hline & Larsen and Mouridsen (1997) [5] & - & High \\
\hline & Howlin et al. (2000) [35] & - & Low \\
\hline & Cederlund et al. (2008) [36] & Sig & Low \\
\hline & Whitehouse et al. (2009) [39] & - & Low \\
\hline Autism score in adolescence & Eaves and Ho (2008) [37] & Sig & Low \\
\hline Age of onset of symptoms & Wolf and Goldberg (1986) [31] & n.s. & Low \\
\hline Evidence of brain injury & Rutter et al. (1967) [28] & n.s. & Low \\
\hline \multicolumn{4}{|l|}{ Severity of disorder } \\
\hline Severity of disorder & Rutter et al. (1967) [28] & Sig & Low \\
\hline \multirow[t]{5}{*}{ Intensity of autistic symptoms } & Wolf and Goldberg (1986) [31] & n.s. & Low \\
\hline & Larsen and Mouridsen (1997) [5] & - & High \\
\hline & Eaves and Ho (2008) [37] & Sig & Low \\
\hline & Whitehouse et al. (2009) [39] & - & Low \\
\hline & Taylor and Seltzer (2010) [40] & Sig & Low \\
\hline \multicolumn{4}{|l|}{ Comorbidity } \\
\hline \multirow[t]{7}{*}{ Psychiatric disorders } & Rumsey et al. (1985) [30] & - & Low \\
\hline & Larsen and Mouridsen (1997) [5] & - & High \\
\hline & Howlin et al. (2000) [35] & - & Low \\
\hline & Cederlund et al. (2008) [36] & Descriptive & Low \\
\hline & Farley et al. (2009) [38] & - & Low \\
\hline & Whitehouse et al. (2009) [39] & Descriptive & Low \\
\hline & Taylor and Seltzer (2010) [40] & n.s. & Low \\
\hline \multirow[t]{2}{*}{ Epilepsy } & Rutter et al. (1967) [28] & n.s. & Low \\
\hline & Farley et al. (2009) [38] & - & Low \\
\hline Other medical disorders & Farley et al. (2009) [38] & - & Low \\
\hline \multicolumn{4}{|l|}{ Personal factors } \\
\hline \multicolumn{4}{|l|}{ Intelligence (IQ-level) } \\
\hline \multirow[t]{5}{*}{ Intelligence (IQ-level) } & Wolf and Goldberg (1986) [31] & - & Low \\
\hline & Ruble and Dalrymple (1996) [34] & Sig & Low \\
\hline & Ballaban-Gil et al. (1996) [4] & Descriptive & Low \\
\hline & Larsen and Mouridsen (1997) [5] & Predictor & High \\
\hline & Billstedt et al. (2010) [41] & Sig & High \\
\hline \multirow[t]{2}{*}{ Full scale IQ } & Szatmari et al. (1989) [32] & - & High \\
\hline & Cederlund et al. (2008) [36] & - & Low \\
\hline IQ at diagnosis & Rutter et al. (1967) [28] & Sig & Low \\
\hline Intelligence at time of admission & Fombonne et al. (1989) [33] & Sig & Low \\
\hline IQ at age 6 & Kobayashi et al. (1992) [3] & Sig & Low \\
\hline Performance IQ at time 1 & Howlin et al. (2000) [35] & - & Low \\
\hline Childhood IQ & Howlin et al. (2004) [7] & Sig & High \\
\hline $\begin{array}{l}\text { Childhood and adolescence } \\
\text { verbal and performance IQ }\end{array}$ & Eaves and Ho (2008) [37] & Sig & Low \\
\hline Historical full scale IQ & Farley et al. (2009) [38] & Sig & Low \\
\hline Intellectual disability & Taylor and Seltzer (2010) [40] & Sig & Low \\
\hline \multirow[t]{3}{*}{ Gender } & Rutter et al. (1967) [28] & n.s. & Low \\
\hline & Wolf and Goldberg (1986) [31] & - & Low \\
\hline & Howlin et al. (2004) [7] & Sig & High \\
\hline
\end{tabular}


Table 5 continued

\begin{tabular}{|c|c|c|c|}
\hline Prognostic factors (independent variables) & Study & Significance & Quality of study \\
\hline \multicolumn{4}{|l|}{ Language/speech } \\
\hline Communication & Ruble and Dalrymple (1996) [34] & Descriptive & Low \\
\hline Language & Ballaban-Gil et al. (1996) [4] & Descriptive & Low \\
\hline \multirow[t]{2}{*}{ Speech and language } & Rumsey et al. (1985) [30] & - & Low \\
\hline & Wolf and Goldberg (1986) [31] & - & Low \\
\hline Language ability (pragmatic or structural problems) & Whitehouse et al. (2009) [39] & - & Low \\
\hline Acquisition of speech for communication & Wolf and Goldberg (1986) [31] & - & Low \\
\hline Early language abilities & Howlin et al. (2000) [35] & Descriptive & Low \\
\hline \multirow[t]{2}{*}{ Level of speech development at age 6} & Kobayashi et al. (1992) [3] & Sig (males) & Low \\
\hline & Farley et al. (2009) [38] & - & Low \\
\hline \multirow[t]{2}{*}{ (Useful) speech at age 5} & Rutter et al. (1967) [28] & Sig & Low \\
\hline & Howlin et al. (2004) [7] & Sig & High \\
\hline Deviant language & Szatmari et al. (1989) [32] & n.s. & High \\
\hline Response to sounds & Rutter et al. (1967) [28] & - & Low \\
\hline \multicolumn{4}{|l|}{ Maladaptive behavior } \\
\hline Ritualistic and compulsive behavior & Rutter et al. (1967) [28] & Descriptive & Low \\
\hline Stereotyped, repetitive and compulsive behavior & Rumsey et al. (1985) [30] & - & Low \\
\hline Bizarre behaviors & Szatmari et al. (1989) [32] & n.s. & High \\
\hline Challenging behaviors & Ruble and Dalrymple (1996) [34] & Descriptive & Low \\
\hline Behavioral difficulties & Ballaban-Gil et al. (1996) [4] & Descriptive & Low \\
\hline \multirow{2}{*}{$\begin{array}{l}\text { Autistic-like stereotyped } \\
\text { and repetitive behavior patterns }\end{array}$} & Howlin et al. (2000) [35] & - & Low \\
\hline & Whitehouse et al. (2009) [39] & - & Low \\
\hline Autistic-type behaviors & Howlin et al. (2004) [7] & - & High \\
\hline Maladaptive behaviors & Taylor and Seltzer (2010) [40] & Sig & Low \\
\hline Adaptive behavior & Farley et al. (2009) [38] & - & Low \\
\hline \multicolumn{4}{|l|}{ Social deficits/impairment } \\
\hline \multirow[t]{3}{*}{ Social deficits/impairment } & Rumsey et al. (1985) [30] & - & Low \\
\hline & Ballaban-Gil et al. (1996) [4] & Descriptive & Low \\
\hline & Whitehouse et al. (2009) [39] & - & Low \\
\hline \multirow{2}{*}{$\begin{array}{l}\text { Impairments in social behavior } \\
\text { (speech and nonverbal communication) }\end{array}$} & Rumsey et al. (1985) [30] & - & Low \\
\hline & Szatmari et al. (1989) [32] & n.s. & High \\
\hline Social functioning & Howlin et al. (2004) [7] & - & High \\
\hline Underactivity/lack of drive/lack of initiative & Rutter et al. (1967) [28] & - & Low \\
\hline Functional independence (ADL) & Taylor and Seltzer (2010) [40] & Sig & Low \\
\hline \multicolumn{4}{|l|}{ External factors } \\
\hline Parents & Rumsey et al. (1985) [30] & - & Low \\
\hline Family income & Taylor and Seltzer (2010) [40] & n.s. & Low \\
\hline History mental illness parent & Rutter et al. (1967) [28] & n.s. & Low \\
\hline Family situation (not living at home) & Rutter et al. (1967) [28] & n.s. & Low \\
\hline Age sent away from home & Lotter (1974) [29] & - & Low \\
\hline Institutionalization & Wolf and Goldberg (1986) [31] & Descriptive & Low \\
\hline Treatment & Rutter et al. (1967) [28] & n.s. & Low \\
\hline \multirow[t]{2}{*}{ Use of medication/pharmacotherapy } & Fombonne et al. (1989) [33] & n.s. & Low \\
\hline & Larsen and Mouridsen (1997) [5] & - & High \\
\hline Schooling & Rutter et al. (1967) [28] & - & Low \\
\hline Amount of schooling & Lotter (1974) [29] & - & Low \\
\hline Age excluded from school & Lotter (1974) [29] & n.s. & Low \\
\hline
\end{tabular}

n.s. Not significant, Sig significant 
latitude and minimal social interaction [13, 30, 35]. As our economy becomes more knowledge-based, and globalization transforms and eliminates unskilled jobs, those with limited cognitive function may become increasingly marginalized [51]. Also periods of employment are alternated by periods of unemployment or temporary jobs [7]. Data of the Dutch Social Security Institute suggest that about $11 \%$ ( $n=1,618$ per year) of the young disabled applying for a social security benefit has ASD [52].

If employed, the majority is working part-time, sometimes less than $10 \mathrm{~h}$ a week [37]. Fulltime work is not always feasible for this group. For successful sustainable work participation a fit between the individual, the job and the work environment is essential [51]. This person-environment fit-or Person-Job fit when focussed on work [53] - concerns the balance between knowledge, skills, abilities, attitude and motivation of the person at the one hand and work and its context at the other hand. A situation of balance contributes to the health, well-being and workfunctioning of the employee. A disbalance leads to stress and disfunctioning. We can distinguish two kinds of PE-fit: the demands-abilities fit and the needs-supply fit [54]. In people with autism both their abilities and their needs can be influenced by the disorder. From a theoretical point of view tailor-made adjustment in demands and supplies (support) may be necessary to ensure a good fit. The practice of part time work might be a reflexion of this.

Considering the severe consequences of autism and the consequential need for special attention for a tailor-made fit between individual and work characteristics, it is important that effective assessments and interventions with respect to work participation of the ASD population are available. Over the last years, special vocational re-integration services and supported employment services have been set up for individuals with ASD, because existing services are not always accessible to them as services sometimes require a basic set of skills of applicants, like interpersonal communication skills, to increase employability $[11,55]$. Part of the supported employment strategy is to adapt the environment and workplace to the needs of disabled individuals who have the skills to do a certain job [56]. According to Garcia-Villamisar [8, 16] supported employment produces favorable results for people with ASD as compared to sheltered employment services with regard to severity of impairments and quality of life. Ridley and Hunter [11] reviewed the practice of supported employment in Scotland and found that the principles of supported employment are not widely and consistently applied, while adherence to these principles is related to improved employment outcomes [57]. Moreover, people with ASD have limited access to these services and unpaid and part-time jobs were more frequently achieved than paid jobs. Leadership by local authorities is needed to improve implementation of supported employment and accessibility. This supports Howlin's [6] claim that the area where an individual lives and the available services is a major influence in outcome with regard to employment.

Autism spectrum disorders are studied extensively since the 70's and more attention is given to social functioning. Unfortunately, only one study focussed on employment as primary outcome. Most of the studies we reviewed were descriptive in nature and thus the quality of the data is variable and often limited. Few studies were able to report significant findings. Moreover, numbers of participants in the studies were often limited. Also quite a few studies in our review consisted of clinical samples, that by the nature of their population have limited generalizing capacity, because of problems with representativeness of these samples. Due to the diverse reporting of outcome it is not possible to compare the studies or to statistically pool the data. For that same reason we did not use the quality assessment for determining levels of evidence for the factors, but to inform the reader about the quality of the studies included. If the results of high quality studies differ from the results of low quality studies, this can be an indication of bias. In our review we found conflicting results for maladaptive behavior between one high and one low quality study $[32,40]$.

Two early studies [28, 29] were conducted in a very different climate with regard to the employment of individuals with disability. Their results seem to indicate that work outcomes did not improve in recent years.

\section{Recommendations}

This review gives an overview of factors facilitating or hindering work participation of people with autism. Factors, identified in high quality studies, can help to provide an evidence-based ground for the development of instruments and intervention programs to increase work participation of individuals with ASD. The availability of adequate services for these individuals during their education, their transition from school to work and to independent living might influence employment outcome considerably [6, 12, 28]. The findings of this review emphasize the need for adequate intervention and services, geared to the needs of the individual with ASD, that help them to adjust to the psychosocial demands in society [39].

However, this review also painfully points to an important gap in the literature regarding predictors of work outcomes in individuals with ASD. High quality studies on predictors of work participation in individuals with ASD are lacking. Most of the included studies reported on outcome as an overall social outcome measure, including work; not on work as a primary outcome measure. In our study we assumed the seventeen factors we found are useful in predicting work outcome. However, further research should focus on work participation as the primary outcome measure in determining 
whether the factors mentioned are indeed influencing work outcome in individuals with ASD. High quality longitudinal studies are needed to identify variables that are responsive to interventions and that take the person-environment fit into account. Only then there is enough base for developing and implementing evidence based strategies to enhance optimal work participation for this group, that could benefit considerably from it in terms of quality of life.
Open Access This article is distributed under the terms of the Creative Commons Attribution Noncommercial License which permits any noncommercial use, distribution, and reproduction in any medium, provided the original author(s) and source are credited.

Table 6 Operationalization of criteria list for quality assessment

\begin{tabular}{|c|c|}
\hline \multirow{9}{*}{$\begin{array}{l}\text { Study } \\
\text { population }\end{array}$} & A Inception cohort \\
\hline & One point if participants are identified at an early uniform point in the course of their disability \\
\hline & Zero point if it is not clear if an inception cohort was used. \\
\hline & B Description of source population \\
\hline & $\begin{array}{l}\text { One point if the source population is described in terms of place of recruitment (for example: Groningen, the Netherlands), } \\
\text { time-period of recruitment and sampling frame of source population (for example: health service provider, special education } \\
\text { services). }\end{array}$ \\
\hline & Zero point if $\leq 2$ features of source population are given. \\
\hline & C Description of relevant inclusion and exclusion criteria \\
\hline & One point if $>2$ criteria are formulated. \\
\hline & Zero point if $\leq 2$ criteria are formulated. \\
\hline \multirow[t]{9}{*}{ Follow-up } & D Follow-up at least 12 months \\
\hline & One point if the follow-up period is at least 12 month and data are provided for this moment in time. \\
\hline & E Drop-outs/loss to follow-up $<20 \%$ \\
\hline & One point if total number of drop-outs/loss to follow up $<20 \%$ \\
\hline & F Information completers versus loss to follow-up/drop-outs \\
\hline & $\begin{array}{l}\text { One point if sociodemographic information is presented for completers and those lost to follow-up/drop outs at baseline, or no } \\
\text { loss to follow-up/drop outs. Reasons for loss to follow-up/drop outs have to be unrelated to the outcome. Loss to follow-up/ } \\
\text { drop outs: all participants of the assembled cohort minus the number of participants at the main moment of measurement for } \\
\text { the main outcome measure, divided by the total number of participants of the assembled cohort. }\end{array}$ \\
\hline & G Prospective data collection \\
\hline & $\begin{array}{l}\text { One point if a prospective design is used, or a historical cohort when the prognostic factors are measured before the outcome } \\
\text { is determined. }\end{array}$ \\
\hline & $\begin{array}{l}\text { Zero point if a historical cohort is used, considering prognostic factors at time zero which are not related to the primary } \\
\text { research question for which the cohort is created, or in case of an ambispective design. }\end{array}$ \\
\hline \multirow[t]{3}{*}{ Treatment } & H Treatment in cohort is fully described/standardized \\
\hline & $\begin{array}{l}\text { One point if treatment subsequent to inclusion into cohort, is fully described and standardized, or in case of no treatment is } \\
\text { given, or if multi-variate correction for treatment is performed in analysis. }\end{array}$ \\
\hline & $\begin{array}{l}\text { Zero point if different treatment is given and if it is not clear how outcome is influenced by it, or if it is not clear whether any } \\
\text { treatment is given. }\end{array}$ \\
\hline \multirow{9}{*}{$\begin{array}{l}\text { Prognostic } \\
\text { factors }\end{array}$} & I Relevant potential prognostic factors \\
\hline & One point if besides socio-demographic factors (age, gender) at least one other factor of the following is described at baseline: \\
\hline & health related factors \\
\hline & personal factors \\
\hline & external factors \\
\hline & J Standardized or valid measurements \\
\hline & $\begin{array}{l}\text { One point if at least one of the factors of I, excluding age and gender, are reported in a standardized or valid way (for } \\
\text { example: questionnaire, structured interview, register, patient-status of health service). }\end{array}$ \\
\hline & K Data presentation of most important prognostic factors \\
\hline & $\begin{array}{l}\text { One point if frequencies, or percentages, or mean (and standard deviation/confidence interval), or median (and Inter Quartile } \\
\text { Range) are reported for the three most important factors of I, namely age, gender and at least one other factor, for the most } \\
\text { important follow-up measurements. }\end{array}$ \\
\hline
\end{tabular}


Table 6 continued

Outcome
One point if at least one of the following outcome criteria is reported: social functioning, independent living, employment,
daily life activities.
M Standardized or valid measurements
One point if one or more of the main outcome measures of L are reported in a standardized or valid way (for example:
questionnaire, structured interview, registration, patient-status of occupational/insurance physician).
$\mathrm{N}$ Data presentation of most important outcome measures
One point if frequencies, or percentages, or mean (and standard deviation/confidence interval), or median (and Inter Quartile
Range) are reported for one or more of the main outcome for the most important follow-up measurements.
O Appropriate univariate crude estimates
One point if univariate crude estimates (RR, OR, HRR) between prognostic factors separately and outcome are presented.
Zero point if only P values or wrong association values (Spearman, Pearson, sensitivity) are given, or if no tests are performed
at all.
P Appropriate multivariate analysis techniques
One point if logistic regression analysis is used, or survival analysis for dichotomous outcomes, or linear regression analysis
for continuous outcomes.
Zero point if no multivariate techniques are performed at all.

\section{References}

1. WHO. International classification of functioning, disability and health (ICF). 2001; resolution WHA 54.21.

2. Waddell G, Burton K, Aylward M. Work and common health problems. J Insur Med. 2007;39:109-20.

3. Kobayashi R, Murata T, Yoshinaga K. A follow-up study of 201 children with autism in Kyushu and Yamaguchi areas, Japan. J Autism Dev Disord. 1992;22:395-411.

4. Ballaban-Gil K, Rapin I, Tuchman R, Shinnar S. Longitudinal examination of the behavioral, language, and social changes in a population of adolescents and young adults with autistic disorder. Pediatr Neurol. 1996;15:217-23.

5. Larsen FW, Mouridsen SE. The outcome in children with childhood autism and Asperger syndrome originally diagnosed as psychotic: a 30-year follow-up study of subjects hospitalized as children. Eur Child Adolesc Psychiatry. 1997;6:181-90.

6. Howlin P. Outcome in adult life for more able individuals with autism or Asperger syndrome. Autism. 2000;4:63-83.

7. Howlin P, Goode S, Hutton J, Rutter M. Adult outcome for children with autism. J Child Psychol Psychiatry. 2004;45:212-29.

8. Garcia-Villamisar D, Ross D, Wehman P. Clinical differential analysis of persons with autism in a work setting: a follow-up study. J Vocat Rehabil. 2000;14:183-5.

9. Hume K, Loftin R, Lantz J. Increasing independence in autism spectrum disorders: a review of three focused interventions. J Autism Dev Disord. 2009;39:1329-38.

10. Kogan MD, Blumberg SJ, Schieve LA, Boyle CA, Perrin JM, Ghandour RM, et al. Prevalence of parent-reported diagnosis of autism spectrum disorder among children in the US, 2007. Pediatrics. 2009; 124:1395-403.

11. Ridley J, Hunter S. The development of supported employment in Scotland. J Vocat Rehabil. 2006;25:57-68.

12. Gerhardt PF, Lainer I. Addressing the needs of adolescents and adults with autism: a crisis on the horizon. J Contemp Psychother. 2011;41:37-45.

13. Jennes-Coussens M, Magill-Evans J, Koning C. The quality of life of young men with Asperger syndrome: a brief report. Autism. 2006;10:403-14.
14. Magill-Evans J, Galambos N, Darrah J, Nickerson C. Predictors of employment for young adults with developmental motor disabilities. Work. 2008;31:433-42.

15. Parmenter TR, Knox M. The post-school experiences of young people with a disability. Int J Rehabil Res. 1991;14:281-91.

16. Garcia-Villamisar D, Wehman P, Navarro MD. Changes in the quality of autistic people's life that work in supported and sheltered employment. A 5-year follow-up study. J Vocat Rehabil. 2002;17:309-12.

17. Eggleton I, Robertson S, Ryan J, Kober R. The impact of employment on the quality of life of people with an intellectual disability. J Vocat Rehabil. 1999;13:95-107.

18. Rutter M. Autistic children: infancy to adulthood. Semin Psychiatry. 1970;2:435-50.

19. Gillberg C. Outcome in autism and autistic-like conditions. J Am Acad Child Adolesc Psychiatry. 1991;30:375-82.

20. Nordin V, Gillberg C. The long-term course of autistic disorders: update on follow-up studies. Acta Psychiatr Scand. 1998;97:99-108.

21. Mawhood L, Howlin P. The outcome of a supported employment scheme for high-functioning adults with autism or Asperger syndrome. Autism. 1999;3:229-54.

22. Gillberg C. Asperger syndrome and high-functioning autism. Br J Psychiatry. 1998;172:200-9.

23. Achterberg TJ, Wind H, de Boer AG, Frings-Dresen MH. Factors that promote or hinder young disabled people in work participation: a systematic review. J Occup Rehabil. 2009;19:129-41.

24. Altman DG. Systematic reviews of evaluations of prognostic variables. BMJ. 2001;323:224-8.

25. Scholten-Peeters GG, Verhagen AP, Bekkering GE, van der Windt DA, Barnsley L, Oostendorp RA, et al. Prognostic factors of whiplash-associated disorders: a systematic review of prospective cohort studies. Pain. 2003;104:303-22.

26. Cornelius LR, van der Klink JJ, Groothoff JW, Brouwer S. Prognostic factors of long term disability due to mental disorders: a systematic review. J Occup Rehabil. 2011;21:259-74.

27. Nonkin Avchen R, Wiggins LD, Devine O, Van Naarden Braun $\mathrm{K}$, Rice C, Hobson NC, et al. Evaluation of a records-review surveillance system used to determine the prevalence of autism spectrum disorders. J Autism Dev Disord. 2011;41:227-36. 
28. Rutter M, Greenfeld D, Lockyer L. A five to fifteen year followup study of infantile psychosis. II. Social and behavioural outcome. Br J Psychiatry. 1967;113:1183-99.

29. Lotter V. Social adjustment and placement of autistic children in Middlesex: a follow-up study. J Autism Child Schiz. 1974;4: $11-32$.

30. Rumsey JM, Rapoport JL, Sceery WR. Autistic children as adults: psychiatric, social, and behavioral outcomes. J Am Acad Child Psychiatry. 1985;24:465-73.

31. Wolf L, Goldberg B. Autistic children grow up: an eight to twenty-four year follow-up study. Can J Psychiat. 1986;31: 550-6.

32. Szatmari P, Bartolucci G, Bremner R, Bond S. A follow-up study of high-functioning autistic children. J Autism Dev Disord. 1989;19:213-25.

33. Fombonne E, Talan I, Bouchard F, Lucas G. A follow-up study of childhood psychosis. Acta Paedopsychiatr. 1989;52:12-25.

34. Ruble LA, Dalrymple NJ. An alternative view of outcome in autism. Focus Autism Other Dev Disabil. 1996;11:3-14.

35. Howlin P, Mawhood L, Rutter M. Autism and developmental receptive language disorder-a follow-up comparison in early adult life. II: social, behavioural, and psychiatric outcomes. J Child Psychol Psychiatry. 2000;41:561-78.

36. Cederlund M, Hagberg B, Billstedt E, Gillberg C, Gillberg IC. Asperger syndrome and autism: a comparative longitudinal follow-up study more than 5 years after original diagnosis. J Autism Dev Disord. 2008;38:72-85.

37. Eaves LC, Ho HH. Young adult outcome of autism spectrum disorders. J Autism Dev Disord. 2008;38:739-47.

38. Farley MA, McMahon WM, Fombonne E, Jenson WR, Miller J, Gardner M, et al. Twenty-year outcome for individuals with autism and average or near-average cognitive abilities. Autism Res. 2009;2:109-18.

39. Whitehouse AJO, Watt HJ, Line EA, Bishop DVM. Adult psychosocial outcomes of children with specific language impairment, pragmatic language impairment and autism. Int $\mathbf{J}$ Lang Commun Disord. 2009;44:511-28.

40. Taylor JL, Seltzer MM. Employment and post-secondary educational activities for young adults with autism spectrum disorders during the transition to adulthood. J Autism Dev Disord. 2011;41:566-74.

41. Billstedt E, Gillberg IC, Gillberg C. Aspects of quality of life in adults diagnosed with autism in childhood: a population-based study. Autism. 2011;15:7-20.

42. Lagerveld SE, Bultmann U, Franche RL, van Dijk FJ, Vlasveld MC, van der Feltz-Cornelis CM, et al. Factors associated with work participation and work functioning in depressed workers: a systematic review. J Occup Rehabil. 2010;20:275-92.

43. Ustun TB, Chatterji S, Bickenbach J, Kostanjsek N, Schneider M. The international classification of functioning, disability and health: a new tool for understanding disability and health. Disabil Rehabil. 2003;25:565-71.

44. Gillberg C, Steffenburg S, Schaumann H. Is autism more common now than ten years ago? Br J Psychiatry. 1991;158:403-9.

45. Beadle-Brown J, Murphy G, Wing L. Long-term outcome for people with severe intellectual disabilities: impact of social impairment. Am J Ment Retard. 2005;110:1-12.

46. Howlin P. Outcome in high-functioning adults with autism with and without early language delays: implications for the differentiation between autism and Asperger syndrome. J Autism Dev Disord. 2003;33:3-13.

47. Volkmar FR, State M, Klin A. Autism and autism spectrum disorders: diagnostic issues for the coming decade. J Child Psychol Psychiatry. 2009;50:108-15.

48. Verdonschot MM, de Witte LP, Reichrath E, Buntinx WH, Curfs LM. Community participation of people with an intellectual disability: a review of empirical findings. J Intellect Disabil Res. 2009;53:303-18.

49. Dusseljee JC, Rijken PM, Cardol M, Curfs LM, Groenewegen PP. Participation in daytime activities among people with mild or moderate intellectual disability. J Intellect Disabil Res. 2011; 55:4-18.

50. Vila M, Pallisera M, Fullana J. Work integration of people with disabilities in the regular labour market: what can we do to improve these processes? J Intellect Dev Disabil. 2007;32:10-8.

51. Kirsh B, Stergiou-Kita M, Gewurtz R, Dawson D, Krupa T, Lysaght R, et al. From margins to mainstream: what do we know about work integration for persons with brain injury, mental illness and intellectual disability? Work. 2009;32:391-405.

52. UWV. UWV Kwartaalverkenning 2009-III. 2009.

53. Edwards J. Person-Job fit: a conceptual integration, literature review and methodological critique. In: Cooper CL, Robinson IT, editors. International review of industrial and organizational psychology. New York: Wiley; 1991. p. 283-357.

54. Edwards J. The relationship between person-environment fit and outcomes: an integrative theoretical framework. In: Ostroff C, Judge TA, editors. Perspectives on organizational fit. San Francisco: Jossey-Bass; 2007. p. 209-58.

55. Lawer L, Brusilovskiy E, Salzer MS, Mandell DS. Use of vocational rehabilitative services among adults with autism. J Autism Dev Disord. 2009;39:487-94.

56. Schneider J. Supported-employment practice in the UK: evidence about an emerging occupational group. Disabil Rehabil. 2008;30: 1819-28.

57. McGrew JH, Griss ME. Concurrent and predictive validity of two scales to assess the fidelity of implementation of supported employment. Psychiatr Rehabil J. 2005;29:41-7. 